\title{
Modeling and Implementation of a Scheduling of Information to maximize processing in a Network Telecommunications
}

\author{
Abdelwahed NAMIR, Souad EZZBADY, Amina El kebbaj and Sanae EL FILALI \\ Laboratory of Modeling and Information Technology, \\ Department of Mathematics and Computer Science,
}

Faculty of Sciences Ben M'sik, Hassan2-Mohammedia University,

B.P 7955, Sidi Othman, Casablanca, Morocco

(1) a.namir@yahoo.fr, (2) souadezzbady@gmail.com,

(3)aminakabaj@gmal.com, (4) elfilalis@gmail.com

\section{ABSTRACT}

The computer networks are based on the Internet protocol conceived from the origin to transport data in more heterogeneous usage (telephony IP, video at request, distributed interactive games, telemedicine, video-conference and audio). These information fluxes or these services before being treated are classified, organized and stocked according to priority rules in different waiting files.

To maximize the treatment of these data, we offer in this work a simple and practical step for modeling and implementing information scheduling in the bandwidth. This step respects the priority rules and eliminates in priori any form of wasting of time at the level of service. It consists of maximizing the use of the bandwidth for different types of traffic in a telecommunication network.

The proposed algorithm consists of serving the traffics that have priorities and to exploit dynamically what remains of the bandwidth in the profile of the least priority traffics while respecting at the very least the part of every traffic in the bandwidth.

The problem is mathematically modeled by an integer linear program (ILP) and in continuation resolute theoretically in general case and numerically in case priority at the level of services. At the end, practical examples to illustrate work are given.

\section{Indexing terms/Keywords}

ILP(integer program linar); Modeling; Network; Optimization; Processing; QoS; Queue; Scheduling

\section{Council for Innovative Research}

Peer Review Research Publishing System

\section{Journal: INTERNATIONAL JOURNAL OF COMPUTERS \& TECHNOLOGY}

Vol 12, No.3 


\section{INTRODUCTION}

Networks of telecommunications have known an unprecedented development which has been accompanied by an important development of their complexity during last decade. The mastery of these complex services requires models and tools allowing to optimize, to assess to improve and to predict the performances of networks.

The appearance of new services including voice, the video at request and distributed interactive games deeply has changed IP architecture. This modification is due to networks with commutation in mode packet which are based on the protocol IP, such as the telephone service which is conceived at origin to transport computer data. This service (phone calls, messages, transfer of files, remote access) results from the heterogeneity of data and from the new techniques of communication which depend on the capacity of network. Such deployment of these services requires a good functioning in terms quality of Service (QoS) on network IP.

Once packets are marked and put in different queues according to the value of the service class identified in the letterhead IP, they will be served by scheduler. This last uses algorithms and disciplines of scheduling which allow controlling the distribution of resources.

For any period, his part or his proportion in the bandwidth according to priority rules are normally reserved for every type of information. It is possible that for the given period ${ }_{\mathrm{n}}$, there are fewer prioritier packets and more less priority packets in queues. Consequently, the bandwidth will not be used at the farthest or maximum. In that case, the processing and the activity of the servers cannot be maximized because of less priority information which can be treated for this period are penalized and leave in next periods. From point of view valuation and performance, this is a bad quality of service since there is increase of the percentage of server inactivity and throughout, the use of the bandwidth for the period will not be maximized. It is in this spirit where is this work, which consists in giving a contribution to the maximization of the processing in a communications network. That is offering a step which models and that implements a scheduling of information to maximize the processing in a telecommunications network. Introduction defined the reflexing frame in which is this work. It introduced the problems approached as well as the contributions in the field of data processing in a communications network. Continuation is constituted of 3 paragraphs: In the 2nd paragraph, they model mathematically the problem put down by an integer linear program (ILP). In the 3rd paragraph, a practical solution and numerical of problem are given when there are priority rules at the level of services. In the 4th paragraph, the work by examples is illustrated. Conclusion takes back the main lines of this study and our contribution. She also shows various continuations and the possible perspectives of this work.

\section{Modeling of problem :}

Once packets are marked and put in different queues according to the value of the service class identified in the letterhead IP, they will be dynamically served by a scheduler in the bandwidth to be processed.

This problem simplifies under following form:

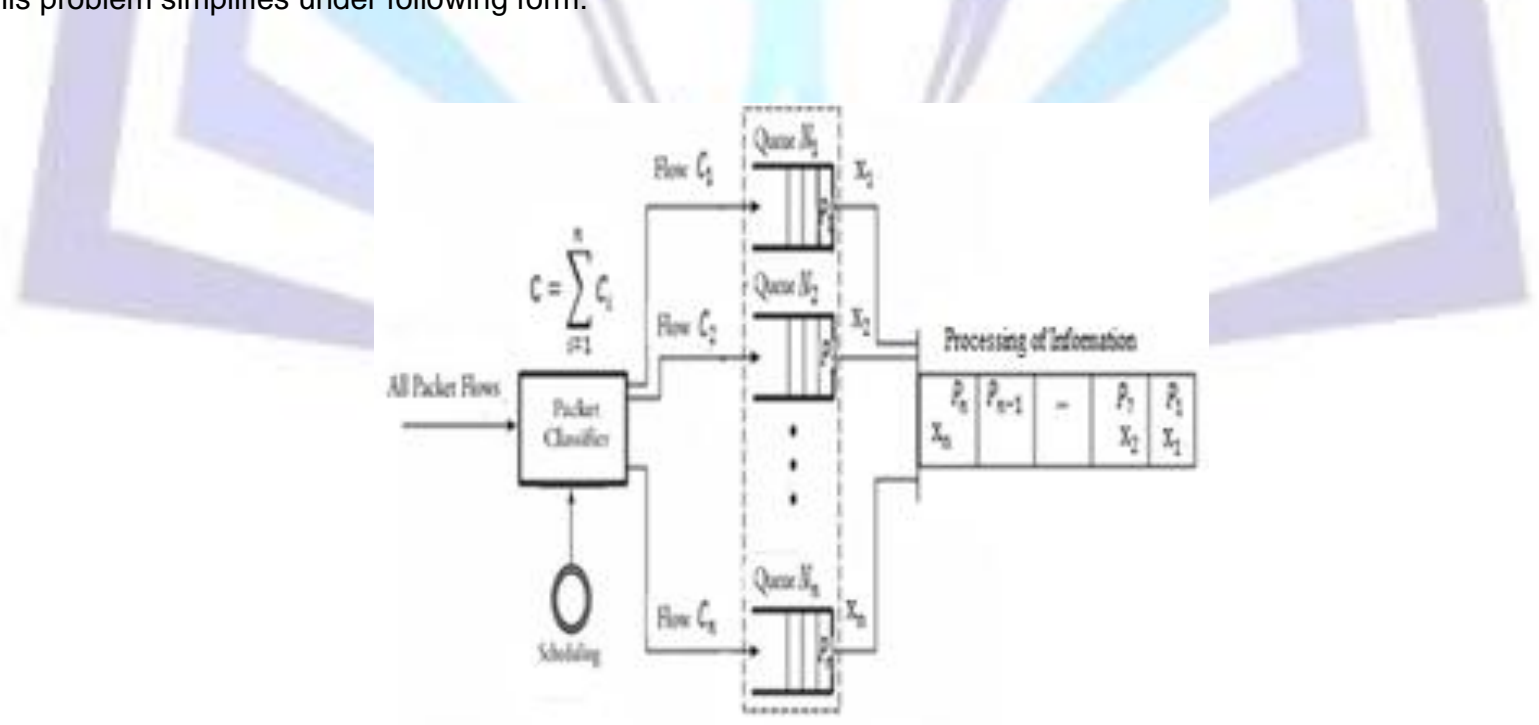

Fig1. Classification and processing of packets

We considered: 
- $\mathrm{N}=$ the number maximum of packets which can be processed during period by the system (capacity of the bandwidth);

- $\mathrm{K}=$ the number of queues in the system (queue $\mathrm{N}_{\mathrm{i}}$ for $1 \leq \mathrm{i} \leq \mathrm{K}$ ) ;

- $\mathrm{p}_{\mathrm{i}}=$ the minimal proportion of packets of the queue $\mathrm{N}_{\mathrm{i}}$ to be processed among all the packets treated by the system periodically, with $1 \leq \mathrm{i} \leq \mathrm{K}$;

For every period $\mathrm{P}_{\mathrm{n}}$ they note:

- $\mathrm{C}_{\mathrm{i}}=$ the number of packets or of giving stocked in the queue $\mathrm{N}_{\mathrm{i}}$ for $1 \leq \mathrm{i} \leq \mathrm{K}$;

- $\mathrm{x}_{\mathrm{i}}=$ the number of packets of the queue $\mathrm{N}_{\mathrm{i}}$ to be processed for $1 \leq \mathrm{i} \leq \mathrm{K}$. This number depends on the state of the queue (presence or not of a flux).

Problem to be solved consists, for given period $\mathrm{P}_{\mathrm{n}}$, in implementing a scheduling of information in the bandwidth to maximize the processing, while respecting constraints and throughout to maximize the use of this bandwidth.

Problem can be mathematically modeled by the model following (ILP):

(S)

$$
\operatorname{Max}\left(\sum_{\mathrm{i}=1}^{\mathrm{K}} \mathrm{x}_{\mathrm{i}}\right)
$$

S. C. $\mathrm{X}_{\mathrm{i}} \leq \mathrm{C}_{\mathrm{i}}$ for $1 \leq \mathrm{i} \leq \mathrm{K}$

$$
\text { S) }\left\{\begin{array}{l}
\sum_{i=1}^{\mathrm{x}_{\mathrm{i}}} \geq \operatorname{Min}\left\{\mathrm{C}_{\mathrm{i}}, \mathrm{p}_{\mathrm{i}} \mathrm{N}\right\} \text { for } 1 \leq \mathrm{i} \leq \mathrm{K} \\
\sum_{\mathrm{x}_{\mathrm{i}} \in \mathbb{N}}^{\mathbb{K}} \mathrm{x}_{\mathrm{i}} \leq \mathrm{N}
\end{array}\right.
$$

Proof: we remark that the number of packets which can be processed at the maximum during period $P_{n}$ is:

$\operatorname{Max}(\mathrm{Z})=\operatorname{Max}\left(\sum_{\mathrm{i}=1}^{\mathrm{K}} \mathrm{x}_{\mathrm{i}}\right)=\operatorname{Min}\left\{\sum_{\mathrm{i}=1}^{\mathrm{K}} \mathrm{C}_{\mathrm{i}}, \mathrm{N}\right\}$

Two cases can present:

First case: $\mathrm{C}=\sum_{\mathrm{i}=1}^{\mathrm{i}=\mathrm{K}} \mathrm{C}_{\mathrm{i}} \leq \mathrm{N} \Rightarrow \operatorname{Max}(\mathrm{Z})=\sum_{\mathrm{i}=1}^{\mathrm{K}} \mathrm{C}_{\mathrm{i}}$

They pose, for $1 \leq \mathrm{i} \leq \mathrm{K}, \mathrm{x}_{\mathrm{i}}=\mathrm{C}_{\mathrm{i}}$. Then $\left(\mathrm{x}_{1}, \mathrm{x}_{2}, \ldots, \mathrm{x}_{\mathrm{K}}\right)$ check contraints and were:

$\mathrm{Z}=\sum_{\mathrm{i}=1}^{\mathrm{i}=\mathrm{K}} \mathrm{C}_{\mathrm{i}}=\operatorname{Max}(\mathrm{Z})$

Therefore it is an optimum solution of problem (S).

Suppose that there exists another solution $\left(\mathrm{x}_{1}^{\prime}, \mathrm{x}_{2}^{\prime}, \ldots, \mathrm{x}_{\mathrm{K}}^{\prime}\right) \neq\left(\mathrm{x}_{1}, \mathrm{x}_{2}, \ldots, \mathrm{x}_{\mathrm{K}}\right)$, then

$\exists \mathrm{j} \in\left\{1_{, \ldots,} \mathrm{K}\right\}$ such as $\mathrm{x}_{\mathrm{j}}^{y} \neq \mathrm{x}_{\mathrm{j}}=\mathrm{C}_{\mathrm{j}}$.

As $\mathrm{x}_{\mathrm{j}}^{\prime} \leq \mathrm{C}_{\mathrm{j}}$, we deduce that $\mathrm{x}_{\mathrm{j}}^{\prime}<\mathrm{C}_{\mathrm{j}}$ and therefore

$\mathrm{Z}=\sum_{\mathrm{i}=1}^{\mathrm{K}} \mathrm{x}_{1}^{\prime}=\sum_{\substack{\mathrm{i}=1 \\ \mathrm{i} \neq \mathrm{j}}}^{\mathrm{K}} \mathrm{x}_{\mathrm{i}}^{\prime}+\mathrm{x}_{\mathrm{j}}^{\prime}<\sum_{\substack{\mathrm{i}=1 \\ \mathrm{i} \neq \mathrm{j}}}^{\mathrm{K}} \mathrm{C}_{\mathrm{i}}+\mathrm{C}_{\mathrm{j}}=\sum_{\mathrm{i}=1}^{\mathrm{K}} \mathrm{C}_{\mathrm{i}}=\operatorname{Max}(\mathrm{Z})$

Contradiction. So $\left(\mathrm{x}_{1}, \mathrm{x}_{2}, \ldots, \mathrm{x}_{\mathrm{K}}\right)$ is a unique solution of problem (S). 
Second case: $\mathrm{C}=\sum_{\mathrm{i}=1}^{\mathrm{i}=\mathrm{K}} \mathrm{C}_{\mathrm{i}}>\mathrm{N} \Rightarrow \operatorname{Max}(\mathrm{Z})=\mathrm{N}$

they consider $\mathrm{N}_{\mathrm{c}}=\left\{\mathrm{i} \in\{1, \ldots, \mathrm{K}\} / \mathrm{C}_{\mathrm{i}}>\mathrm{p}_{\mathrm{i}} \mathrm{N}\right\}$, they pose:

$$
\mathrm{x}_{\mathrm{i}}=\left\{\begin{array}{cl}
\mathrm{C}_{\mathrm{i}} & \text { si } \mathrm{i} \notin \mathrm{N}_{\mathrm{c}} \\
\mathrm{r}_{\mathrm{i}} \text { with } \mathrm{r}_{\mathrm{i}} \in\left[\mathrm{p}_{\mathrm{i}} \mathrm{N}_{s} \mathrm{C}_{\mathrm{i}}\right] \text { and } \sum_{\mathrm{i} \in \mathbb{N}_{c}} \mathrm{r}_{\mathrm{i}}=\mathrm{N}-\sum_{\mathrm{i} \in \mathbb{N}_{c}} \mathrm{C}_{\mathrm{i}} \text { si } \mathrm{i} \in \mathrm{N}_{c}
\end{array}\right.
$$

Then $\left(\mathrm{x}_{1}, \mathrm{x}_{2}, \ldots, \mathrm{x}_{\mathrm{K}}\right)$ check contraints and

$\sum_{\mathrm{i}=1}^{\mathrm{i}=\mathrm{K}} \mathrm{x}_{\mathrm{i}}=\sum_{\mathrm{i} \in \mathrm{N}_{\mathrm{c}}} \mathrm{r}_{\mathrm{i}}+\sum_{\mathrm{i} \notin \mathbb{N}_{\mathrm{e}}} \mathrm{C}_{\mathrm{i}}=\mathrm{N}=\operatorname{Max}(\mathrm{Z})$

Therefore it is an optimum solution of problem (S).

Remark: If $C=\sum_{i=1}^{i=K} C_{i}>N$ then solution is not unique, in general.

\section{The resolution method}

The solution that we propose is, for each period, to reserve for $1 \leq i \leq K, \operatorname{Min}\left\{C_{i}, p_{i} N\right\}$ packets queue $N_{i}$ bandwidth and supplemented by the remaining queue respecting the order of priority.

Proposition : If queues in order of importance are organized by giving priority to the first queue $\mathrm{N} 1$ then the second queue N2 then the third queue N3 and so on, they have optimum solution of (S) following:

$$
\text { (1) }\left\{\begin{array}{l}
x_{1}=\operatorname{Min}\left\{C_{1}, N-\sum_{i=2}^{K} \operatorname{Min}\left\{C_{i}, p_{i} N\right\}\right\} \\
x_{i}=\operatorname{Min}\left\{C_{\tilde{i}}, N-\sum_{j=1}^{i-1} x_{j}-\sum_{j=i+1}^{K} \operatorname{Min}\left\{C_{j}, p_{j} N\right\}\right\} \text { for } 2 \leq i \leq K \\
x_{K}=\operatorname{Min}\left\{C_{K} N-\sum_{j=1}^{K-1} x_{j}\right\}
\end{array}\right.
$$

\section{Proof:}

1st case: $\mathrm{C}=\sum_{\mathrm{i}=1}^{\mathrm{i}=\mathrm{K}} \mathrm{C}_{\mathrm{i}} \leq \mathrm{N}$

In that case $\mathrm{x}_{\mathrm{i}}=\mathrm{C}_{\mathrm{i}}$ for $1 \leq \mathrm{i} \leq \mathrm{K} \Rightarrow \operatorname{Max}(\mathrm{Z})=\sum_{\mathrm{i}=1}^{\mathrm{K}} \mathrm{C}_{\mathrm{i}}$.

2nd case: $\mathrm{C}=\sum_{\mathrm{i}=1}^{\mathrm{i}=\mathrm{K}} \mathrm{C}_{\mathrm{i}}>\mathrm{N}$

They reserve in the bandwidth, $\mathrm{x}_{\mathrm{i}}=\operatorname{Min}\left\{\mathrm{C}_{i}, \mathrm{p}_{\mathrm{i}} \mathrm{N}\right\}$ packets of the queue $N_{i}$ for $1 \leq \mathrm{i} \leq \mathrm{K}$. There remain $\mathrm{N}-\sum_{\mathrm{i}=1}^{\mathrm{K}} \operatorname{Min}\left\{\mathrm{C}_{\mathrm{i}}, \mathrm{p}_{\mathrm{i}} \mathrm{N}\right\}$ packets there to be affected.

- As the queue $\mathrm{N}_{1}$ is the 1 st priority $1 \mathrm{st}$, they change, if it is necessary, the value of $\mathrm{x}_{1}$ by :

$$
\mathrm{x}_{1}=\operatorname{Min}\left\{\mathrm{C}_{1}, \operatorname{Min}\left\{\mathrm{C}_{1}, \mathrm{p}_{1} \mathrm{~N}\right\}+\mathrm{N}-\sum_{\mathrm{i}=1}^{\mathrm{K}} \operatorname{Min}\left\{\mathrm{C}_{\mathrm{i}}, \mathrm{p}_{\mathrm{i}} \mathrm{N}\right\}\right\}
$$

That is to say:

$$
\mathrm{x}_{1}=\operatorname{Min}\left\{\mathrm{C}_{1}, \mathrm{~N}-\sum_{\mathrm{i}=2}^{\mathrm{K}} \operatorname{Min}\left\{\mathrm{C}_{\mathrm{i}}, \mathrm{p}_{\mathrm{i}} \mathrm{N}\right\}\right\}
$$


$\mathrm{x}_{1}$ check constraint:

$\operatorname{Min}\left\{\mathrm{C}_{1}, \mathrm{p}_{1} \mathrm{~N}\right\} \leq \mathrm{x}_{1} \leq \mathrm{C}_{1}$

Because

$\operatorname{Min}\left\{\mathrm{C}_{1}, \mathrm{p}_{1} \mathrm{~N}\right\} \leq \mathrm{p}_{1} \mathrm{~N}=\mathrm{N}-\sum_{\mathrm{i}=2}^{\mathrm{K}} \mathrm{p}_{\mathrm{i}} \mathrm{N} \leq \mathrm{N}-\sum_{\mathrm{i}=2}^{\mathrm{K}} \operatorname{Min}\left[\mathrm{C}_{\mathrm{i}}, \mathrm{p}_{\mathrm{i}} \mathrm{N}\right]$

There remain $\mathrm{N}-\mathrm{x}_{1}-\sum_{\mathrm{i}=2}^{\mathrm{K}} \mathrm{Min}\left\{\mathrm{C}_{\mathrm{i}}, \mathrm{p}_{\mathrm{i}} \mathrm{N}\right\}$ packets there to be affected.

- Then, as the queue $\mathrm{L}_{2}$ is the 2 nd priority, they change, if it is necessary, the value of $\mathrm{x}_{2}$ by :

$\mathrm{x}_{2}=\operatorname{Min}\left\{\mathrm{C}_{2}, \operatorname{Min}\left\{\mathrm{C}_{2}, \mathrm{p}_{2} \mathrm{~N}\right\}+\mathrm{N}-\mathrm{x}_{1}-\sum_{\mathrm{i}=2}^{\mathrm{K}} \operatorname{Min}\left\{\mathrm{C}_{\mathrm{i}}, \mathrm{p}_{\mathrm{i}} \mathrm{N}\right\}\right\}$

That is to say:

$\mathrm{x}_{2}=\operatorname{Min}\left\{\mathrm{C}_{1}, \mathrm{~N}-\mathrm{x}_{1}-\sum_{\mathrm{i}=3}^{\mathrm{K}} \operatorname{Min}\left\{\mathrm{C}_{\mathrm{i}}, \mathrm{p}_{\mathrm{i}} \mathrm{N}\right\}\right)$

$\mathrm{x}_{2}$ check constraint:

$\operatorname{Min}\left\{\mathrm{C}_{2}, \mathrm{p}_{2} \mathrm{~N}\right\} \leq \mathrm{x}_{2} \leq \mathrm{C}_{2}$

Because

$\mathrm{x}_{1} \leq \mathrm{N}-\sum_{\mathrm{i}=2}^{\mathrm{K}} \operatorname{Min}\left\{\mathrm{C}_{\mathrm{i}}, \mathrm{p}_{\mathrm{i}} \mathrm{N}\right\}=\mathrm{N}-\operatorname{Min}\left\{\mathrm{C}_{2}, \mathrm{p}_{2} \mathrm{~N}\right\}-\sum_{\mathrm{i}=3}^{\mathrm{K}} \operatorname{Min}\left\{\mathrm{C}_{\mathrm{i}}, \mathrm{p}_{\mathrm{i}} \mathrm{N}\right\}$

That is to say:

$$
\operatorname{Min}\left\{\mathrm{C}_{2}, \mathrm{p}_{2} \mathrm{~N}\right\} \leq \mathrm{N}-\mathrm{x}_{1}-\sum_{\mathrm{i}=3}^{\mathrm{K}} \operatorname{Min}\left\{\mathrm{C}_{\mathrm{i}}, \mathrm{p}_{\mathrm{i}} \mathrm{N}\right\}
$$

There remain $\mathrm{N}-\mathrm{x}_{1}-\mathrm{x}_{2}-\sum_{\mathrm{i}=3}^{\mathrm{K}} \operatorname{Min}\left\{\mathrm{C}_{\mathrm{i}}, \mathrm{p}_{\mathrm{i}} \mathrm{N}\right\}$ packets there to be affected.

- So in succession...

As $\mathrm{C}=\sum_{\mathrm{i}=1}^{\mathrm{i}=\mathrm{K}} \mathrm{C}_{\mathrm{i}}>\mathrm{N}$ and $\sum_{\mathrm{i}=1}^{\mathrm{i}=\mathrm{K}} \mathrm{p}_{\mathrm{i}} \mathrm{N}=\mathrm{N}$ there is $\mathrm{K}^{\prime} \in\{1,2, \ldots, \mathrm{K}-1\}$ such as:

$\mathrm{N}-\sum_{\mathrm{i}=1}^{\mathrm{K}^{\prime}} \mathrm{x}_{\mathrm{i}}-\sum_{\mathrm{i}=\mathrm{K}^{\prime}+1}^{\mathrm{K}} \operatorname{Min}\left\{\mathrm{C}_{\mathrm{i}}, \mathrm{p}_{\mathrm{i}} \mathrm{N}\right\}=0$

That is to say, from $K^{\prime}+1, x_{i}$ can't be changed and therefore:

$\mathrm{x}_{\mathrm{i}}=\operatorname{Min}\left\{\mathrm{C}_{\mathrm{i}}, \mathrm{p}_{\mathrm{i}} \mathrm{N}\right\}$ pour $\mathrm{K}^{\prime}+1 \leq \mathrm{i} \leq \mathrm{K}$

So

$$
\sum_{\mathrm{i}=1}^{\mathrm{K}} \mathrm{x}_{\mathrm{i}}=\mathrm{N} \Rightarrow \mathrm{Z}=\mathrm{N}
$$

What justifies that solution given by equations (1) is an optimum solution of the system (S).

\section{Examples of application}

In these examples, taking that $\mathrm{K}=4, \mathrm{~N}=400$ and the queues are privilege as follows:

- Queue N1 $\rightarrow$ high priority (Example voice) ; 
- Queue N2 $\rightarrow$ medium priority (Example Data) ;

- Queue N3 $\rightarrow$ normal priority (Example Multimedia) ;

- Queue N4 $\rightarrow$ low priority (Example downloading).

Table 1. the numerical resultats for different examples in the case of $K=4$ and $N=400$

\begin{tabular}{|c|l|l|l|c|c|c|c|c|c|c|c|c|c|}
\hline $\mathbf{p}_{1}$ & $\mathbf{p}_{\mathbf{2}}$ & $\mathbf{p}_{3}$ & $\mathbf{p}_{\mathbf{4}}$ & $\mathbf{C}_{\mathbf{1}}$ & $\mathbf{C}_{2}$ & $\mathbf{C}_{3}$ & $\mathbf{C}_{\mathbf{4}}$ & $\mathbf{x}_{1}$ & $\mathbf{x}_{2}$ & $\mathbf{x}_{\mathbf{3}}$ & $\mathbf{x}_{\mathbf{4}}$ & $\sum_{i=1}^{K} C_{i}$ & $\mathbf{Z}$ \\
\hline $100 \%$ & $0 \%$ & $0 \%$ & $0 \%$ & 0 & 0 & 20 & 80 & 0 & 0 & 20 & 80 & 100 & 100 \\
\hline $100 \%$ & $0 \%$ & $0 \%$ & $0 \%$ & 400 & 200 & 30 & 40 & 400 & 0 & 0 & 0 & 670 & 400 \\
\hline $60 \%$ & $20 \%$ & $15 \%$ & $5 \%$ & 400 & 300 & 20 & 100 & 280 & 80 & 20 & 20 & 820 & 400 \\
\hline $90 \%$ & $7 \%$ & $3 \%$ & $0 \%$ & 0 & 0 & 0 & 50 & 0 & 0 & 0 & 50 & 50 & 50 \\
\hline $75 \%$ & $20 \%$ & $4 \%$ & $1 \%$ & 100 & 200 & 60 & 100 & 100 & 200 & 60 & 40 & 460 & 400 \\
\hline $60 \%$ & $20 \%$ & $15 \%$ & $5 \%$ & 400 & 300 & 20 & 100 & 0 & 0 & 20 & 80 & 100 & 100 \\
\hline
\end{tabular}

\section{Simulation of resultat}

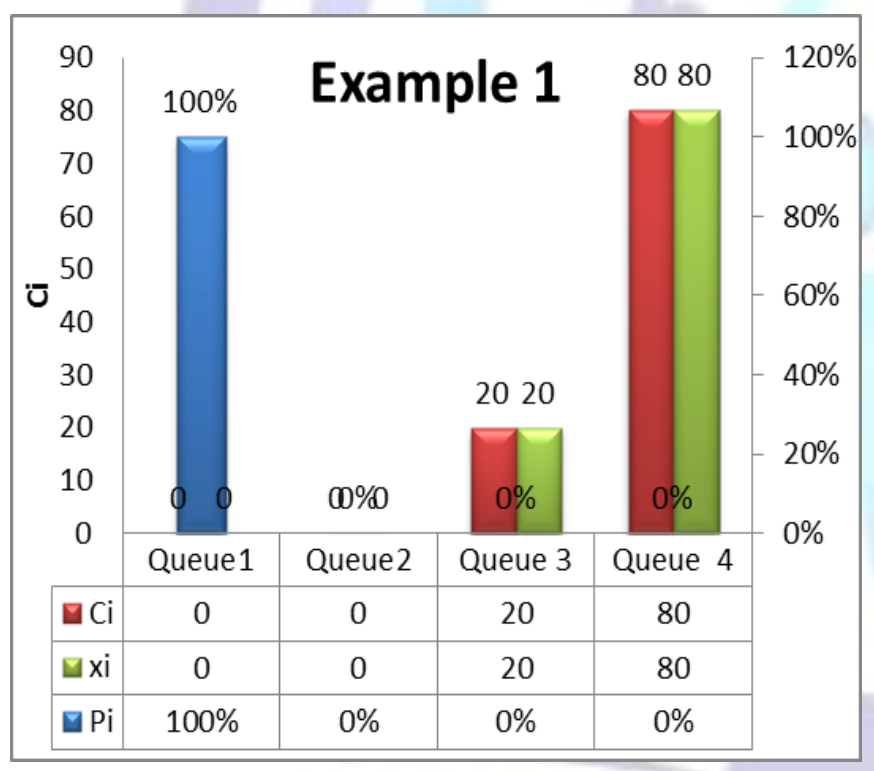

FIG2 EXAMPLE 1 FOR THE CASE: $\mathrm{K}=4, \mathrm{~N}=400$

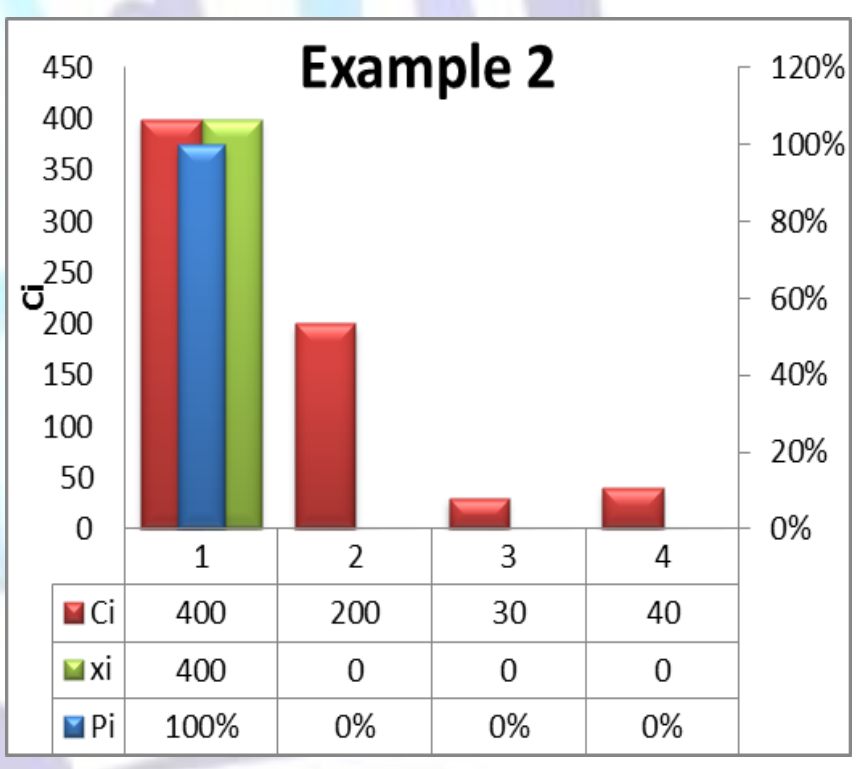

FIG3 EXAMPLE 2 FOR THE CASE: $\mathrm{K}=4, \mathrm{~N}=400$ 


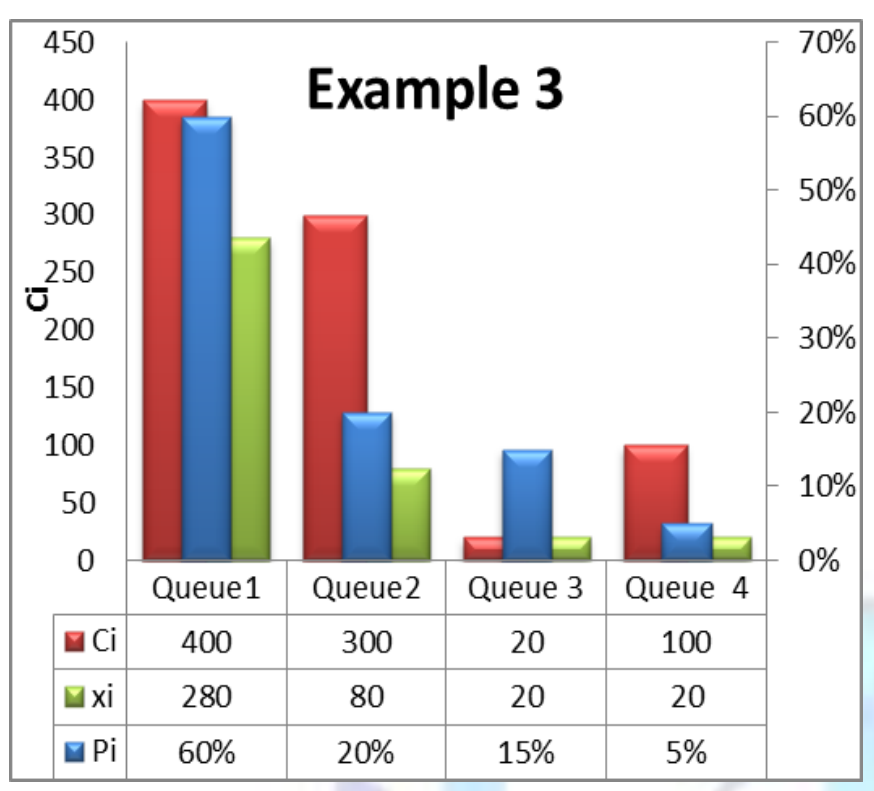

FIG4 EXAMPLE 3 FOR THE CASE: $\mathrm{K}=4, \mathrm{~N}=400$

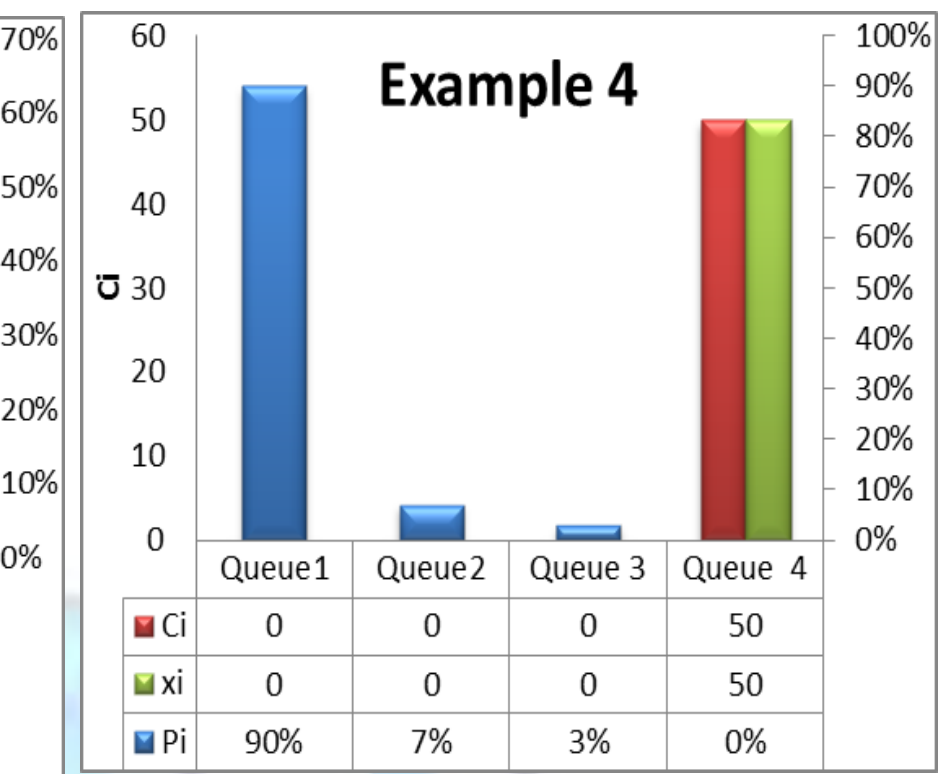

FIG5 EXAMPLE 4 FOR THE CASE: $\mathrm{K}=4, \mathrm{~N}=400$

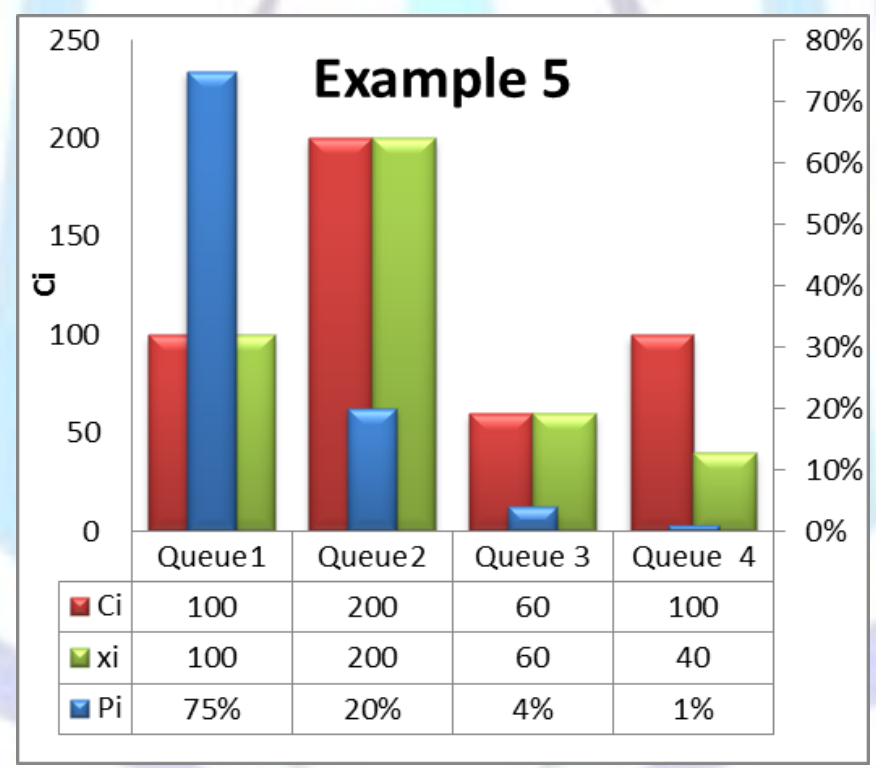

FIG6 EXAMPLE 5 FOR THE CASE: $\mathrm{K}=4, \mathrm{~N}=400$

\section{5 . CONCLUSION}

The accomplished work consists in conceiving a practical and pragmatic step of implementation of a scheduling of information to maximize the treatment in a network for given period $\mathrm{P}_{\mathrm{n}}$. So, a method of mathematical modeling and a numerical resolution described above was offered.

This work opens the way to our sense towards various research perspectives which are on two plans: a plan of deepening of accomplished research and plan of widening of research domain.

As for the deepening of offered work, he would be interesting at first of:

- $\quad$ use the algorithm of GOMORY to solve numerically the program (s).

- $\quad$ offer or conceive practical tools of the implementation of offered step;

- defecate step by studying the roles of the actors and define them for every stage of step. 
As for widening of the domain of research, he would be interesting of:

- $\quad$ link up this step with the governance of information systems;

- guarantee QOS at the level of routing of information;

- $\quad$ find a solution in case of surcharge who could degrade severely the service level given in the different fluxes;

- Resolve the problem of loss of packets in the case of saturation of queues.

\section{References}

[1] A. NAMIR, E. LABRIJI, M. RACHIK et N. YOUSFI. Cours et Travaux Dirigés de Recherche Opérationnelle Programmation Linéaire. Edition Université Hassan II-Mohammedia, 2007.

[2] Andrew S. Tanenbaum, (2003) "Computer Networks", Fourth Edition, Pearson Education.

[3] BUFFA, Elwood. Operations Management, 3e édition, New York, John Wiley \& Sons, 1972.

[4] FRITZSIMMONS, James A. et Mona J. FRITZSIMMONS. Service management : Operations, Strategy and Information Technology, 3e édition, New York, Irwin/McGraw-Hill, 2001.

[5] GRIFFIN, W. Queuing : Basic Theory and Applications, Columbus, Ohio, Grid Publishing, 1978.

[6] H. Zhang, (1995) "Service disciplines for guaranteed performance service in packet switching networks", proceedings of the IEEE, 83(10):1374-1399.

[7] HILLIER, Frederick S., Mark S. HILLIER and Gerald J. LIEBERMAN. Introduction to Management Science : A Modeling and Case Studies Approach with Spreadsheets, New York, Irwin/McGraw-Hill, 2000.

[8] KARTZ, K. L., B. M. LARSON et R. C. LARSON. «Prescriptions for the Waiting-in-Line Blues : Entertain, Enlighten, and Engage », Sloan Management Review, vol. 32, n², hiver 1991, p. 44-53.

[9] L.Toumi. Algorithmes et mécanismes pour la qualité de service dans des réseaux hétérogènes. Thèse de doctorat, Institut National Polytechnique de Grenoble, Décembre 2002.

[10] M. BADIA : Qualité de Service et Intelligence Artificielle: Application pour les Réseaux Hétérogènes des Télécommunications Optiques. Thèse de Doctorat d'Etat en Mathématiques \& Informatique, Faculté des Sciences Ben M'Sik de Casablanca soutenue le 17/07/2010.

[11] Octavio Napoléon Medina Carvajal. ' Etude des algorithmes d'attribution de priorités dans un Internet à différenciation de services. Thèse de doctorat, Université de Rennes I, March 2001. (fifo).

[12] P. Goyal, H. M. Vin, and H. Chen, (1996) "Start-time Fair Queuing: A scheduling algorithm for integrated services", proceedings of the ACM-SIGCOMM '96, Palo Alto, CA, pp 157-168.

[13] S. Blake, D. Black, M. Carlson, E. Davies, Z. WAng, and W. Weiss. An architecture for differentiated services. Technical report, Request for Comments (Proposed Standard) RFC 2475, IETF, December 1998.

[14] S. EZZBADY, A. NAMIR, A. BOULAL et S. EL FILALI. Gestion de l'information dans un réseau de communication : Modélisation et Maximisation. MACS-6, Oujda, 24-26 octobre 2013.

[15] S. EZZBADY, A. NAMIR, A. BOULAL, S. EL FILALI et A. BADI. Modeling and maximizing treatiment in a network of Telecommunication. 10ième édition des Journées d'Analyse Numérique \& Optimisation, EST, Essaouira, 31 octobre au 2 novembre 2013.

[16] S. EZZBADY, A. NAMIR, S. EL FILALI et A. BOULAL. Contribution au traitement de l'information dans un réseau intelligent. Journée des Sciences de l'Ingénieur, Faculté des Sciences Ben M'Sik, Casablanca le 6 juillet 2013.

[17] S. EZZBADY, A. NAMIR, S. EL FILALI et A. BOULAL. Modélisation d'un type d'ordonnancement de l'information dans un réseau intelligent. Journée de Mathématiques et Applications, Faculté des Sciences Ben M'Sik, Casablanca le 29 juin 2013.

[18] STEVENSON, William J. Introduction to Management Science, 2e édition, Burr Ridge, IL., Richard D. Irwin, 1992. 